\title{
24-hour central aortic systolic pressure and 24-hour central pulse pressure are related to diabetic complications in type 1 diabetes - a cross-sectional study
}

Simone Theilade ${ }^{1 *}$, Maria Lajer ${ }^{1}$, Tine Willum Hansen ${ }^{1}$, Christel Joergensen ${ }^{1}$, Frederik Persson ${ }^{1}$, Gudbjörg Andrésdottir ${ }^{1}$, Henrik Reinhard ${ }^{1}$, Stine Elkjær Nielsen ${ }^{1}$, Peter Lacy², Bryan Williams ${ }^{2}$ and Peter Rossing 1,3,4

\begin{abstract}
Background: Non-invasive measurements of 24 hour ambulatory central aortic systolic pressure (24 h-CASP) and central pulse pressure (24 h-CPP) are now feasible. We evaluate the relationship between $24 \mathrm{~h}$ central blood pressure and diabetes-related complications in patients with type 1 diabetes.

Methods: The study was cross-sectional, including 715 subjects: 86 controls (C), 69 patients with short diabetes duration ( $<10$ years), normoalbuminuria $(<30 \mathrm{mg} / 24 \mathrm{~h}$ ) without receiving antihypertensive treatment (SN), 211 with longstanding diabetes ( $\geq 10$ years) and normoalbuminuria (LN), 163 with microalbuminuria (30-299 mg/24 h) (Mi) and 186 with macroalbuminuria (> $300 \mathrm{mg} / 24 \mathrm{~h}$ ) (Ma).

24 h-CASP and 24 h-CPP was measured using a tonometric wrist-watch-like device (BPro, HealthStats, Singapore) and derived using N-point moving average.

Results: In C, SN, LN, Mi and Ma mean \pm SD 24 h-CASP was: $114 \pm 17,115 \pm 13,121 \pm 13,119 \pm 16$ and $121 \pm$ $13 \mathrm{mmHg}(p<0.001)$; and $24 \mathrm{~h}-\mathrm{CPP}: 38 \pm 8,38 \pm 7,44 \pm 10,46 \pm 11$ and $46 \pm 11 \mathrm{mmHg},(p<0.001)$.

Following rigorous adjustment ( $24 \mathrm{~h}$ mean arterial pressure and conventional risk factors), $24 \mathrm{~h}$-CASP and $24 \mathrm{~h}$-CPP increased with diabetes, albuminuria degree, previous cardiovascular disease (CVD), retinopathy and autonomic dysfunction ( $p \leq 0.031$ ).

Odds ratios per 1 standard deviation increase in 24 h-CASP, 24 h-CPP and $24 \mathrm{~h}$ systolic blood pressure (24 h-SBP) were for CVD: 3.19 (1.68-6.05), 1.43 (1.01-2.02) and 2.39 (1.32-4.33), retinopathy: 4.41 (2.03-9.57), 1.77 (1.17-2.68) and 3.72 (1.85-7.47) and autonomic dysfunction: 3.25 (1.65-6.41), 1.64 (1.12-2.39) and 2.89 (1.54-5.42).
\end{abstract}

Conclusions: 24 h-CASP and 24 h-CPP was higher in patients vs. controls and increased with diabetic complications independently of covariates. Furthermore, $24 \mathrm{~h}$-CASP was stronger associated to complications than 24 h-SBP.

The prognostic significance of 24 h-CASP and 24 h-CPP needs to be determined in follow-up studies.

Trial registration: ClinicalTrials.gov ID NCT01171248.

Keywords: Ambulatory blood pressure, Brachial systolic blood pressure, Central aortic systolic pressure, Central pulse pressure, Diabetic complications, Type 1 diabetes

\footnotetext{
* Correspondence: ktld@steno.dk

${ }^{1}$ Steno Diabetes Center, Niels Steensensvej 1, 2820 Gentofte, Denmark

Full list of author information is available at the end of the article
} 


\section{Background}

Blood pressure (BP) control is of paramount importance in prevention of complications in type 1 diabetes [1-3]. Despite improved medical therapy over recent decades, complications still impact many diabetic patients diminishing quality of life and contributing to premature mortality. Moreover, monitoring and managing complications in patients with type 1 diabetes confers significant healthcare expenditure [4], and improved screening, monitoring and prevention strategies are warranted.

Routinely, seated BP measurements are recorded over the brachial artery in the physician's office. However, increasing evidence points towards superior predictive value of out-of-office measurements such as 24 hour ambulatory BP (AMBP) [5] and home BP monitoring [6]. Recent studies indicate additional benefit from non-invasive assessment of central aortic systolic pressure (CASP) and central pulse pressure (CPP) as compared to routine measurement of brachial pressure [7-9].

Central and brachial pressures are mutually influenced by cardiac output, vascular resistance and conduit artery rigidity. Whilst mean arterial pressure (MAP) is relatively constant across large arteries, systolic pressure waves are amplified as they move from the aortic root to the brachial artery. This amplification results in a higher brachial systolic BP (SBP) relative to the corresponding CASP [10]. With aging [11] and/or diabetes [12] alterations in large artery composition associated with increased arterial stiffness, augmented blood flow and increased pressure wave reflections, impact more on CASP relative to SBP. In addition, antihypertensive treatment (AHT) may alter the relationship between CASP and SBP, resulting in different effects on CASP relative to SBP $[13,14]$. This might underpin different outcome benefits between classes of AHT drugs despite targeting to similar levels of SBP [15].

Measurement of ambulatory $24 \mathrm{~h}$-CASP and $24 \mathrm{~h}$-CPP are now feasible, and a recent study showed a difference in central and brachial diurnal patterns, which could imply that central BP possess additional prognostic value [16]. We investigate the associations between $24 \mathrm{~h}$-CASP and $24 \mathrm{~h}-\mathrm{CPP}$, and impaired kidney function, history of cardiovascular disease (CVD), left ventricular hypertrophy $(\mathrm{LVH})$, retinopathy, and autonomic dysfunction in patients with type 1 diabetes.

\section{Methods}

\section{Study population}

Between September 2009 and June 2011, Caucasian patients with TIDM, were recruited to enter a cross-sectional study at Steno Diabetes Center, Copenhagen, Denmark. Recruitment was in sequential order according to date of birth from a list of all patients attending the outpatient clinic. For power calculations we used an $\alpha$-value of 5\%, a $\beta$-value of $20 \%$, and an estimated variance of $9.5 \mathrm{mmHg}$.
For the comparison between controls and patients we estimated a $24 \mathrm{~h}$-CASP-difference of $4 \mathrm{mmHg}$ between groups, which implied that we needed a minimum of 45 participants in each group. For the comparisons between patient groups (3 albuminuria groups), we estimated a 24 h-CASP-difference of $2 \mathrm{mmHg}$, indicating a need for 177 patients in each group. Thus, we intended to include at least 45 controls and 576 patients. Of 1285 patients invited, 676 (52.6\%) agreed to enter the study. Patients declining participation were younger but with similar gender distribution compared to participating patients (49 \pm 16 years and $57 \%$ males vs. $54 \pm 13$ years and $56 \%$ males $(p<0.001$ and 0.62$)$. In addition, a control group of 51 non-diabetic subjects from Copenhagen, Denmark and 46 non-diabetic subjects from Leichester, UK were included.

In total, 654 (96.7\%) patients and 90 (92.9\%) controls had adequate ambulatory AMBP available, with $46 \pm 7$ and $18 \pm 3$ (63.9\% and $75.0 \%$ of total possible) recordings during day and night, respectively. Four controls and 25 patients with normoalbuminuria and short diabetes duration received $\mathrm{AHT}$ and were excluded in order to create two comparable groups not treated for hypertension. The remaining groups of patients had no restriction regarding AHT (Table 1). Hence, the analysed cohort included 715 subjects, comprising of 86 non-diabetic persons (C), 69 patients with short diabetes duration $(<10$ years), normoalbuminuria ( $<30 \mathrm{mg} / 24 \mathrm{~h}$ ) and not receiving AHT (SN), 211 patients with longstanding diabetes ( $\geq 10$ years) and normoalbuminuria (LN), 163 patients with microalbuminuria (30-299 mg/24 h) (Mi), and $186 \mathrm{pa}-$ tients with macroalbuminuria (>300 mg/24 h) (Ma). Figure 1 summarise the inclusion and exclusion of the study participants. The 10 year cut-off for defining patients as having short $v s$. long duration of diabetes was chosen, as complications to diabetes may develop within 5-10 years [17]. The five groups were stratified in order to create groups for comparison of 1) healthy controls to patients without complications, 2) healthy controls to patients with sustained normal kidney function, and 3) patients with increasing degree of impaired kidney function.

Patients with ESRD, defined as receiving dialysis or renal transplantation, or GFR/eGFR $<15 \mathrm{ml} / \mathrm{min} / 1.73 \mathrm{~m}^{2}$ were not included.

The study conformed to the Declaration of Helsinki, was approved by the Danish National Committee on Biomedical Research Ethics (2009-056), and all participants gave written informed consent.

\section{Clinical and laboratory methods}

Participant attended one single study visit, during which all clinical and laboratory measurements were performed. For office BP, 15 minutes supine rest was followed by recording and averaging of three separate left brachial measurements (A\&D Medical, UA787). 
Table 1 Baseline characteristics by group

\begin{tabular}{|c|c|c|c|c|c|c|c|c|}
\hline & \multirow{2}{*}{$\begin{array}{l}\text { All patients } \\
n=629\end{array}$} & \multirow{2}{*}{$\begin{array}{l}\text { Controls } \\
\mathrm{n}=86\end{array}$} & \multicolumn{2}{|c|}{ Normoalbuminuria } & \multicolumn{2}{|c|}{ Elevated albuminuria } & \multirow{2}{*}{$\begin{array}{l}\text { Controls vs. short } \\
\text { duration, normo- } \\
\text { albuminuria } \\
p\end{array}$} & \multirow{2}{*}{$\begin{array}{c}\text { Long duration, } \\
\text { normo- vs. micro- vs. } \\
\text { macroalbuminuria } \\
p\end{array}$} \\
\hline & & & $\begin{array}{l}\text { Short duration } \\
n=69\end{array}$ & $\begin{array}{l}\text { Long duration } \\
\qquad \mathrm{n}=211\end{array}$ & $\begin{array}{c}\text { Micro } \\
n=163\end{array}$ & $\begin{array}{c}\text { Macro } \\
n=186\end{array}$ & & \\
\hline Female (\%) & 44 & 44 & 39 & 53 & 38 & 42 & 0.84 & 0.010 \\
\hline Age (years) & $54 \pm 13$ & $49 \pm 12$ & $39 \pm 13$ & $57 \pm 11$ & $58 \pm 13$ & $55 \pm 10$ & $<0.001$ & 0.031 \\
\hline Diabetes duration (years) & $34 \pm 15$ & $\mathrm{n} / \mathrm{a}$ & $6 \pm 3$ & $38 \pm 11$ & $35 \pm 15$ & $38 \pm 11$ & N/A & 0.056 \\
\hline $\mathrm{HbA}_{1 \mathrm{c}}(\mathrm{mmol} / \mathrm{mol})$ & $64 \pm 13$ & $35 \pm 3$ & $65 \pm 13$ & $62 \pm 10$ & $65 \pm 13$ & $68 \pm 14$ & $<0.001$ & $<0.001$ \\
\hline Total cholesterol (mmol/l) & $4.7 \pm 0.9$ & $5.5 \pm 0.9$ & $4.7 \pm 0.8$ & $4.8 \pm 0.7$ & $4.6 \pm 0.8$ & $4.6 \pm 1.0$ & $<0.001$ & 0.23 \\
\hline Body mass index $\left(\mathrm{kg} / \mathrm{m}^{2}\right)$ & $25.5 \pm 5.9$ & $26.6 \pm 5.2$ & $24.2 \pm 3.2$ & $25.0 \pm 3.8$ & $25.8 \pm 4.1$ & $26.3 \pm 9.1$ & 0.001 & 0.045 \\
\hline eGFR $\left(\mathrm{ml} / \mathrm{min} / 1.73 \mathrm{~m}^{2}\right)$ & $83 \pm 28$ & $96 \pm 16$ & $107 \pm 21$ & $90 \pm 20$ & $85 \pm 26$ & $62 \pm 29$ & $<0.001$ & $<0.001$ \\
\hline *UAER (mg/24-h) & $18(2-8271)$ & $14(4-157)$ & $10(4-39)$ & $7(2-236)$ & $33(4-4512)$ & $130(4-8271)$ & 0.36 & $<0.001$ \\
\hline Smokers (\%) & 21 & 6 & 23 & 18 & 19 & 25 & 0.002 & 0.18 \\
\hline Antihypertensive treatment (\%) & 71 & 0 & 0 & 56 & 90 & 98 & N/A & $<0.001$ \\
\hline Cardiovascular disease (\%) & 21 & 4 & 1 & 14 & 30 & 29 & 0.14 & $<0.001$ \\
\hline Left ventricular hypertrophy (\%) & 4 & 7 & 7 & 4 & 4 & 4 & 0.91 & 0.82 \\
\hline Autonomic dysfunction (\%) & 60 & 7 & 7 & 53 & 64 & 83 & 0.48 & $<0.001$ \\
\hline Retinopathy (\%) & 81 & 0 & 23 & 83 & 84 & 96 & $<0.001$ & $<0.001$ \\
\hline
\end{tabular}

Data represents percentage (\%), mean \pm SD or median (range). P-values are for unadjusted comparisons (ANOVA) between groups.

"Some patients with previously persistent macroalbuminuria had values $<300 \mathrm{mg} / 24 \mathrm{~h}$ at the time of investigation. 


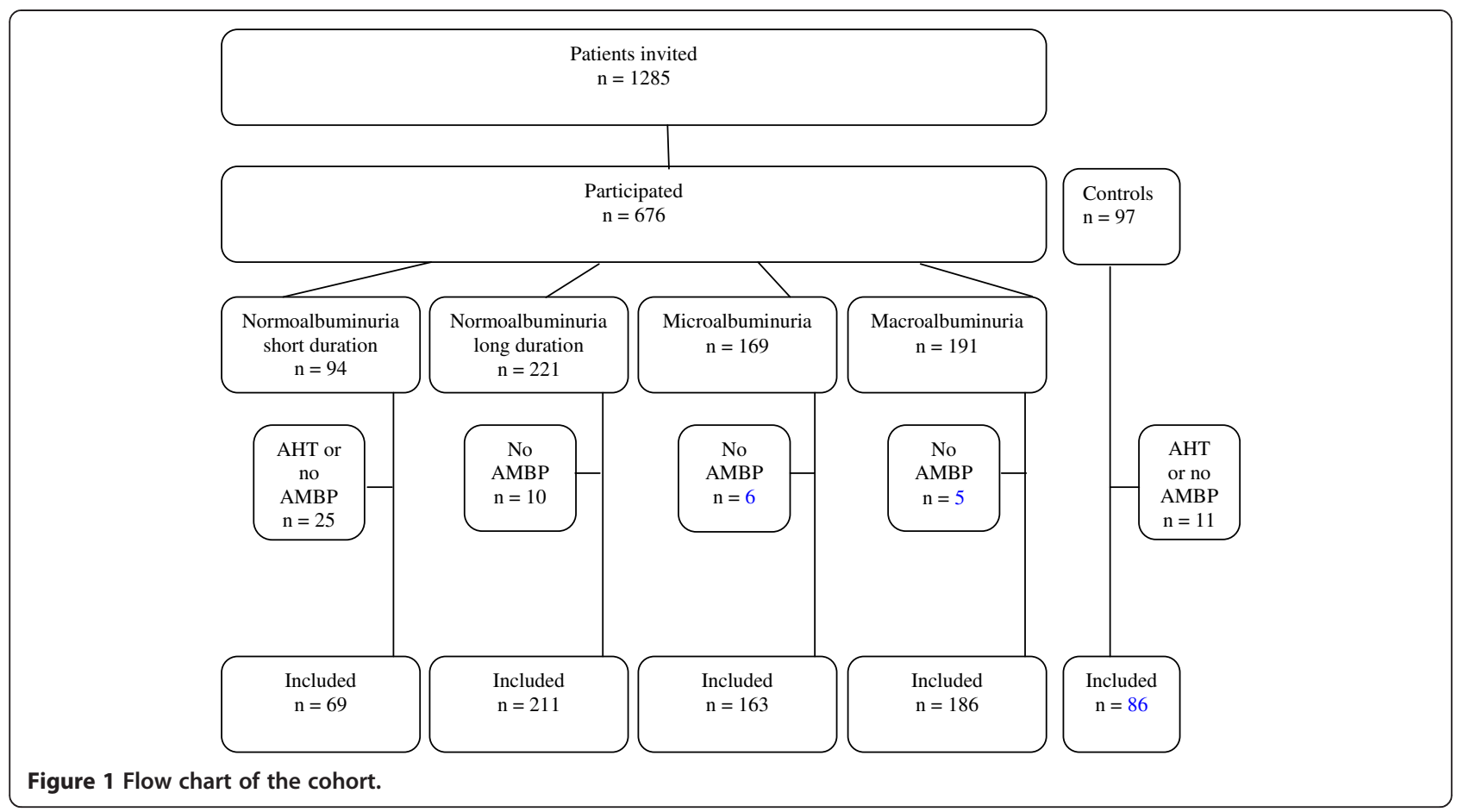

AMBP were recorded non-invasively, using a validated system consisting of a radial arterial tonometer embedded in an articulating strap of a wrist-watch device (BPro ${ }^{\mathrm{Tm}}$, HealthStats Singapore). The device was calibrated to brachial BP and variations in pulse waveform height over the subsequent measurement period used to calculate brachial AMBP [18]. Calibrated radial waveforms were then processed at the end of each measurement session by applying an N-point-moving average to derive CASP [19]. The device reported CASP, CPP, SBP, diastolic BP (DBP), MAP and heart rate (HR) every 15 minutes during $24 \mathrm{~h}$. Previous validation studies have shown the BPro device to obtain BP measurements independently of arm positioning, with values comparable to those obtained with cuff-based devices $[20,21]$. Furthermore, we have shown that CASP measurements obtained by the BPro are comparable to those obtained by accepted gold standard devices for non-invasive measurements of CASP [22]. AMBP data was considered adequate if $\geq 14$ and $\geq 7$ recordings were obtained during day- and nighttime [23].

Following 15 minutes supine rest, office measurements of central BP were obtained with the SphygmoCor device (Atcor Medical, Sydney, Australia) by trained laboratory technicians according to guidelines.

Electrocardiographs (ECG) were recorded with Cardiosoft V6.51 (GE Healthcare, USA) and LVH defined according to Sokolow-Lyon, Cornell and/or Romhilt-Estes score [24] by the investigating M.D. Heart rate variability (HRV) was measured after 15 minutes supine rest, during paced deep breathing [25] to classify autonomic dysfunction. HRV was assessed by expiration/inspiration variation in heart rate. While resting in supine position, the patient was asked to breathe deeply at the rate of 6 breaths per minute for 1 minute, during which an electrocardiogram was recorded. Subsequently the means of the difference in highest and lowest heart rates (HR) during each breathing cycle were calculated. An abnormal value was $<11$ beats per minute. Retinopathy status obtained from medical records, and assessed from retinal photographs, taken every 3-24 months, were classified as normal if no retinopathy was present, and abnormal if presence of simple or proliferative retinopathy or blindness.

All participants had blood samples and phenotypic characteristics collected. $\mathrm{HbA}_{1 \mathrm{c}}$ was measured by highperformance liquid chromatography (Variant; Biorad Laboratories, Germany), urinary albumin excretion rate (UAER) was measured in $24 \mathrm{~h}$ sterile urine collections by enzyme immunoassay, and plasma creatinine concentration by an enzymatic method (Hitachi 912, Roche Diagnostics, Germany).

Patients were stratified as normoalbuminuric if two out of three consecutive measurements contained normoalbuminuria with UAER $<30 \mathrm{mg} / 24 \mathrm{~h}$, and micro- or macroalbuminuric if UAER was or previously recorded between 30-299 mg/24 h or above $300 \mathrm{mg} / 24 \mathrm{~h}$, in two out of three consecutive measurements, respectively. Estimated GFR (eGFR) was calculated by the four 
variable Modification of Diet in Renal Disease (MDRD) formula. Based on standardized questionnaires, current daily use of $\geq 1$ cigarettes/cigars/pipes classified smokers. Previous of CVD was myocardial infarction, stroke, or peripheral arterial disease based on standardized WHO questionnaires and patient records from Steno Diabetes Center.

\section{Statistical analysis}

Normally distributed variables are given as mean \pm SD. The non-normally distributed variable (UAER) is given as median (range) and log10 transformed before analysis. Comparisons between groups were performed by unpaired Student's t-test or analysis of variance (ANOVA).

Univariate and mulitivariate linear regression compared hemodynamic variables with covariates. Analysis of covariance (ANCOVA) was applied for multivariable adjustment when comparing hemodynamic variables in different groups and in patients with or without complications. Adjustments were made for gender, age, $24 \mathrm{~h}-\mathrm{MAP}, 24 \mathrm{~h}-\mathrm{HR}$, eGFR, $\mathrm{HbA}_{1 \mathrm{c}}$, smoking and antihypertensive treatment. In comparisons including controls $\mathrm{HbA}_{1 \mathrm{c}}$ and antihypertensive treatment was left out.

The multivariate logistic regression between hemodynamic variables and diabetic complications also included UAER and office CASP, CPP or SBP. Although for LVH the analyses were only adjusted for gender, age and 24 h-MAP.

A two-tailed $p$-value of $<0.05$ was considered statistically significant. Statistical analyses were performed using SPSS for Windows, version 20.0 (SPSS, Chicago, IL).

\section{Results}

\section{Baseline}

Characteristics of the analysed cohort consisting of 629 patients and 86 controls are shown in Tables 1 and 2 . Patients included and excluded from the analyses had similar age, diabetes duration, gender distribution, $\mathrm{HbA}_{1 \mathrm{c}}$, total cholesterol, eGFR, UAER, pulse wave velocity, HRV, frequency of previous CVD, retinopathy status and presence of LVH $(p>0.11)$. Table 3 represent the estimated marginal means adjusted for gender, age, $24 \mathrm{~h}$-MAP, $24 \mathrm{~h}-\mathrm{HR}, \mathrm{UAER}, \mathrm{eGFR}, \mathrm{HbA}_{1 \mathrm{c}}$, smoking and antihypertensive treatment.

Correlations between covariates and 24 h-CASP, 24 $\mathrm{h}$-CPP and $24 \mathrm{~h}$-SBP in all participants are shown in Table 4. In short, all three blood pressures correlated with age, diabetes duration, 24 h-MAP, 24 h-HR, UAER and eGFR. Furthermore, 24 h-CPP correlated with total cholesterol, 24 h-SBP was higher in men, and all three blood pressures were higher in patients receiving AHT. None of the three blood pressures correlated with $\mathrm{HbA}_{1 \mathrm{c}}$ or body mass index.

In adjusted analyses only age, diabetes duration, 24 h-MAP, $24 \mathrm{~h}-\mathrm{HR}$ and UAER correlated with $24 \mathrm{~h}$-CASP, $24 \mathrm{~h}-\mathrm{CPP}$ and $24 \mathrm{~h}-\mathrm{SBP}(p \leq 0.001)$.
Correlations between 24 h-CASP and 24-SBP were high $(\mathrm{r}=0.99, p<0.001$ for $24 \mathrm{~h}$, daytime and nighttime BPs). For comparison, the correlation between office CASP measured by SphygmoCor and supine brachial SBP was also high $(\mathrm{r}=0.96, p<0.001)$, indicative of an overall close relation between CASP and brachial SBP. However, despite the close correlation, there was a scatter between central and brachial measurements as seen in Figure 2 . Moreover, correlations between $24 \mathrm{~h}-\mathrm{CPP}$ and $24 \mathrm{~h}-\mathrm{SBP}$ was much lower $(\mathrm{r}=0.72, p<0.001$ for $24 \mathrm{~h}$, daytime and nighttime BPs). As was the correlation between 24 $\mathrm{h}$-CASP and office CASP $(\mathrm{r}=0.67, p<0.001)$.

\section{$24 \mathrm{~h}$-CASP and $24 \mathrm{~h}$-CPP comparison between groups}

$\mathrm{C}$ and SN had similar $24 \mathrm{~h}$-CASP and 24 h-CPP (unadjusted $p=0.60$ and 0.96 ; adjusted $p=0.39$ and 0.59 ) (Tables 2 and 3). Including further adjustment for body mass index and total cholesterol did not alter these results $(p \geq 0.61)$. Controls compared to all normoalbuminuric patients (SN and LN) had lower $24 \mathrm{~h}$-CASP and $24 \mathrm{~h}$-CPP (38 \pm 8 and $114 \pm 17 v s .43 \pm 10$ and $119 \pm 14 \mathrm{mmHg}$, respectively) ( $p<0.001$ and 0.004; adjusted $p<0.001$ for both). Additional adjustment for body mass index and total cholesterol did not alter these results $(p=0.016$ and 0.018).

Between the groups with LN, Mi, and Ma, 24 h-CASP was lowest in Mi albeit not statistically significant $(p=$ 0.19 ), while $24 \mathrm{~h}$-CPP was almost similar between groups $(p=0.14)$ (Table 2). Following adjustment, both 24 h-CASP and 24 h-CPP was associated with increased albuminuria group ( $p<0.001$ for both) (Table 3). If investigating level of albuminuria as a continuous variable in all patients, both $24 \mathrm{~h}$-CASP and $24 \mathrm{~h}$-CPP were independently associated with UAER $(p \leq 0.001)$

\section{$24 \mathrm{~h}$-CASP, $24 \mathrm{~h}$-CPP and $24 \mathrm{~h}$-SBP in patients with vs. without history of CVD}

The $24 \mathrm{~h}$-CASP, $24 \mathrm{~h}$-CPP and $24 \mathrm{~h}$-SBP in patients with $(\mathrm{n}=134(21.3 \%)) v$ s. without a history of CVD was $121 \pm 14,49 \pm 11$ and $127 \pm 16$ vs. $119 \pm 14,43 \pm 10$ and $129 \pm 16 \mathrm{mmHg}(p=0.43,<0.001$ and $=0.18)$. Following adjustment, 24 h-CASP, $24 \mathrm{~h}-\mathrm{CPP}$ and 24-h SBP was higher in patients with a history of CVD $(p<0.001$ for all). Per 1 standard deviation (SD) increase in 24 h-CASP, $24 \mathrm{~h}$-CPP and 24-h SBP the odds ratio (OR) for previous CVD was 3.2 (1.7-6.1), 1.4 (1.0-2.0) and 2.4 (1.3-4.3) $(p<0.001,=0.045$ and $=0.004)$ (adjusted for gender, age, 24 h-MAP, 24 h-HR, UAER, eGFR, $\mathrm{HbA}_{1 c}$, smoking, AHT, and either office CASP, office CPP or office SBP (Table 5). If total cholesterol and body mass index was further included in the adjusted model, $p$ values for a history of CVD were 0.001 for 24 h-CASP, 0.053 for $24 \mathrm{~h}$-CPP and 0.05 for $24 \mathrm{~h}$-SBP. 
Table 2 Hemodynamic variables by group

\begin{tabular}{|c|c|c|c|c|c|c|c|}
\hline & \multirow{2}{*}{$\begin{array}{l}\text { Controls } \\
\mathrm{n}=86\end{array}$} & \multicolumn{2}{|c|}{ Normoalbuminuria } & \multicolumn{2}{|c|}{ Elevated albuminuria } & \multirow{2}{*}{$\begin{array}{l}\text { Controls vs. short } \\
\text { duration, normo- } \\
\text { albuminuria } \\
p\end{array}$} & \multirow{2}{*}{$\begin{array}{c}\text { Long duration, } \\
\text { normo- vs. micro- vs. } \\
\text { macroalbuminuria } \\
p\end{array}$} \\
\hline & & $\begin{array}{l}\text { Short duration } \\
\qquad n=69\end{array}$ & $\begin{array}{l}\text { Long duration } \\
\qquad n=211\end{array}$ & $\begin{array}{c}\text { Micro } \\
n=163\end{array}$ & $\begin{array}{c}\text { Macro } \\
n=186\end{array}$ & & \\
\hline $24 \mathrm{~h}-\mathrm{CASP}(\mathrm{mmHg})$ & $114 \pm 17$ & $115 \pm 13$ & $121 \pm 14$ & $119 \pm 16$ & $121 \pm 13$ & 0.60 & 0.19 \\
\hline Daytime CASP (mmHg) & $118 \pm 18$ & $119 \pm 14$ & $124 \pm 14$ & $122 \pm 16$ & $124 \pm 13$ & 0.59 & 0.26 \\
\hline Nighttime CASP (mmHg) & $107 \pm 16$ & $108 \pm 14$ & $114 \pm 13$ & $112 \pm 16$ & $116 \pm 14$ & 0.68 & 0.029 \\
\hline Office CASP (mmHg) & $117 \pm 20$ & $112 \pm 14$ & $118 \pm 18$ & $120 \pm 18$ & $120 \pm 20$ & 0.057 & 0.079 \\
\hline $24 \mathrm{~h}-\mathrm{CPP}(\mathrm{mmHg})$ & $38 \pm 8$ & $38 \pm 7$ & $44 \pm 10$ & $46 \pm 11$ & $46 \pm 11$ & 0.96 & 0.14 \\
\hline Daytime CPP (mmHg) & $39 \pm 8$ & $39 \pm 8$ & $45 \pm 10$ & $46 \pm 11$ & $46 \pm 11$ & 0.59 & 0.13 \\
\hline Nighttime CPP (mmHg) & $36 \pm 8$ & $36 \pm 7$ & $42 \pm 10$ & $44 \pm 11$ & $45 \pm 11$ & 0.68 & 0.059 \\
\hline $24 \mathrm{~h}$ brachial SBP $(\mathrm{mmHg})$ & $122 \pm 19$ & $124 \pm 15$ & $129 \pm 15$ & $127 \pm 17$ & $131 \pm 15$ & 0.43 & 0.18 \\
\hline Daytime brachial SBP (mmHg) & $127 \pm 19$ & $129 \pm 15$ & $134 \pm 15$ & $132 \pm 17$ & $134 \pm 15$ & 0.37 & 0.24 \\
\hline Nighttime brachial SBP (mmHg) & $113 \pm 19$ & $115 \pm 15$ & $121 \pm 14$ & $119 \pm 17$ & $124 \pm 15$ & 0.52 & 0.043 \\
\hline Mean arterial pressure $(\mathrm{mmHg})$ & $91 \pm 14$ & $93 \pm 11$ & $94 \pm 10$ & $91 \pm 10$ & $94 \pm 11$ & 0.43 & 0.011 \\
\hline $24 \mathrm{~h}$ heart rate (beats per minute) & $66 \pm 7$ & $67 \pm 7$ & $70 \pm 8$ & $69 \pm 9$ & $74 \pm 10$ & 0.31 & $<0.001$ \\
\hline
\end{tabular}
Data are mean \pm SD.
$p$-values are for unadjusted comparisons (ANOVA) for comparison of controls to patients with short duration of normoalbuminuria or between patients with longstanding normoalbuminuria, microalbuminuria

CASP: central aortic systolic pressure, CPP: central pulse pressure, SBP: systolic blood pressure. 
Table 3 Blood pressure variables given as adjusted estimated means for type 1 diabetes patients

\begin{tabular}{|c|c|c|c|c|c|c|c|}
\hline & \multirow{2}{*}{$\begin{array}{l}\text { Controls } \\
\mathrm{n}=86\end{array}$} & \multicolumn{2}{|c|}{ Normoalbuminuria } & \multicolumn{2}{|c|}{ Elevated albuminuria } & \multirow{2}{*}{$\begin{array}{l}\text { Controls vs. short } \\
\text { duration, normo- } \\
\text { albuminuria } \\
p\end{array}$} & \multirow{2}{*}{$\begin{array}{c}\text { Long duration, } \\
\text { normo-vs. micro- vs } \\
\text { macroalbuminuria } \\
p\end{array}$} \\
\hline & & $\begin{array}{c}\text { Short duration } \\
n=69\end{array}$ & $\begin{array}{c}\text { Long duration } \\
n=211\end{array}$ & $\begin{array}{c}\text { Micro } \\
n=163\end{array}$ & $\begin{array}{c}\text { Macro } \\
n=186\end{array}$ & & \\
\hline $24 \mathrm{~h}-\mathrm{CASP}(\mathrm{mmHg})$ & $117(116-119)$ & $118(117-119)$ & $119(118-120)$ & $121(120-121)$ & $122(121-122)$ & 0.39 & $<0.001$ \\
\hline Daytime CASP (mmHg) & $122(120-123)$ & $122(121-123)$ & $121(121-122)$ & $123(123-124)$ & $125(124-126)$ & 0.60 & $<0.001$ \\
\hline Nighttime CASP (mmHg) & $109(107-111)$ & $110(109-112)$ & $112(111-114)$ & $114(113-115)$ & $116(115-117)$ & 0.30 & $<0.001$ \\
\hline Office CASP (mmHg) & $110(107-112)$ & $111(109-113)$ & $119(117-121)$ & $120(118-122)$ & $118(115-120)$ & 0.44 & 0.41 \\
\hline $24 \mathrm{~h}-\mathrm{CPP}(\mathrm{mmHg})$ & $38(36-40)$ & $39(37-41)$ & $43(42-44)$ & $46(44-47)$ & $47(46-49)$ & 0.59 & $<0.001$ \\
\hline Daytime CPP (mmHg) & $39(37-41)$ & $40(38-41)$ & $43(42-45)$ & $46(45-48)$ & $48(46-49)$ & 0.74 & $<0.001$ \\
\hline Nighttime CPP (mmHg) & $36(34-38)$ & $37(35-39)$ & $41(40-43)$ & $44(43-45)$ & $46(44-47)$ & 0.54 & $<0.001$ \\
\hline $24 \mathrm{~h}$ brachial SBP $(\mathrm{mmHg})$ & $126(125-128)$ & $126(125-128)$ & $128(126-129)$ & $130(127-131)$ & $131(130-132)$ & 0.98 & $<0.001$ \\
\hline Daytime brachial SBP (mmHg) & $132(129-134)$ & $132(130-134)$ & $132(130-134)$ & $134(133-135)$ & $135(134-136)$ & 0.90 & 0.001 \\
\hline Nighttime brachial SBP $(\mathrm{mmHg})$ & $116(114-118)$ & $117(115-119)$ & $119(118-121)$ & $122(120-123)$ & $123(122-125)$ & 0.56 & 0.001 \\
\hline 24 h-MAP $(\mathrm{mmHg})$ & $92(89-95)$ & $92(90-95)$ & 95 (94-97) & $92(90-93)$ & $92(90-94)$ & 0.80 & 0.004 \\
\hline $24 \mathrm{~h}$ heart rate (beats per minute) & $65(63-67)$ & $67(66-69)$ & $72(70-73)$ & $70(68-71)$ & $73(71-74)$ & 0.08 & 0.005 \\
\hline
\end{tabular}

Estimated marginal means with $95 \%$ confidence intervals. P-values are for adjusted comparisons (ANCOVA) of controls to patients with short duration of normoalbuminuria or for comparison between patients with longstanding normoalbuminuria, microalbuminuria and macroalbuminuria. Adjustments were made for gender, age, $24 \mathrm{~h}-\mathrm{MAP}$ (except for $24 \mathrm{~h}-\mathrm{MAP}$ ), $24 \mathrm{~h} \mathrm{HR}$, eGFR and smoking. Adjustments also included HbA $\mathrm{Ac}_{\mathrm{c}}$ and antihypertensive treatment when comparing patients with normoalbuminuria and long diabetes duration, microalbuminuria and macroalbuminuria.

CASP: central aortic systolic pressure, CPP: central pulse pressure, SBP: systolic blood pressure, MAP: mean arterial pressure, microalbuminuria: $30-299 \mathrm{mg} / 24 \mathrm{~h}$, macroalbuminuria > $300 \mathrm{mg} / 24 \mathrm{~h}$. 
Table 4 Correlations between 24 h-CASP, 24 h brachial SBP or 24 h-CPP and covariates in all participants ( $n=715$ )

\begin{tabular}{llll}
\hline & 24 $\mathbf{h}$ brachial SBP & $\mathbf{2 4} \mathbf{h}$-CASP & $\mathbf{2 4} \mathbf{h}$-CPP \\
\hline Office CASP & $r=0.64, p<0.001$ & $r=0.67, p<0.001$ & $r=0.56, p<0.001$ \\
24 h-MAP & N/A & $r=0.90, p<0.001$ & $r=0.32, p<0.001$ \\
24 h-heart rate & $r=0.12, p=0.002$ & 0.17 & $r=0.13, p<0.001$ \\
logUAER & $r=0.18, p<0.001$ & $r=0.17, p<0.001$ & $r=0.18, p<0.001$ \\
Diabetes duration & $r=0.13, p=0.01$ & $r=0.12, p=0.001$ & $r=0.40, p<0.001$ \\
Age & $r=0.11, p=0.03$ & $r=0.12, p=0.001$ & $r=0.40, p<0.001$ \\
eGFR & $r=0.12, p=0.02$ & $r=0.12, p=0.02$ & $r=0.23, p<0.001$ \\
HbA ${ }_{1 c}$ & 0.71 & 0.78 & 0.94 \\
Total cholesterol & 0.11 & 0.10 & $r=0.08, p=0.039$ \\
Body mass index & 0.30 & 0.38 & 0.71 \\
Gender & Male $>$ female, $p=0.02$ & 0.21 & 0.19 \\
Antihypertensive treatment & Highest in treated patients, $p<0.001$ & Highest in treated patients, $p<0.001$ & Highest in treated patients, $p<0.001$ \\
Smoking & 0.43 & 0.65 & 0.46 \\
\hline
\end{tabular}

r-values are Pearson's coefficients.

MAP: mean arterial pressure, UAER: urinary albumin excretion rate, eGFR: estimated glomerular filtration rate.

* Since SBP is included in MAP.

$24 \mathrm{~h}$-CASP, $24 \mathrm{~h}$-CPP and $24 \mathrm{~h}$-SBP in patients with vs. without LVH

The 24 h-CASP, $24 \mathrm{~h}$-CPP and $24 \mathrm{~h}$-SBP in patients with $(\mathrm{n}=27(4.3 \%))$ vs. without $\mathrm{LVH}$ were $125 \pm 11$, $48 \pm 11$ and $132 \pm 15$ vs. $119 \pm 14,44 \pm 10$ and $128 \pm$ $16 \mathrm{mmHg}$ ( $p=0.001,0.019$ and 0.13$)$. Following adjustment for gender, age and $24 \mathrm{~h}$-MAP the significance attenuated $(p=0.09,0.10$ and 0.06). Per 1 SD increase in $24 \mathrm{~h}$-CASP, $24 \mathrm{~h}$-CPP and $24 \mathrm{~h}-\mathrm{SBP}$, the OR for LVH was $2.5(1.0-6.5), 1.5(1.0-2.3)$ and $2.1(0.9-5.0)(p=$ $0.057,0.061$, and 0.079 ) (Table 5).
$24 \mathrm{~h}-\mathrm{CASP}, 24 \mathrm{~h}-\mathrm{CPP}$ and $24 \mathrm{~h}-\mathrm{SBP}$ in patients with vs. without retinopathy

In patients with $(\mathrm{n}=507(80.6 \%))$ vs. without retinopathy, $24 \mathrm{~h}$-CASP, $24 \mathrm{~h}$-CPP and $24 \mathrm{~h}-\mathrm{SBP}$ was $121 \pm 14$, $46 \pm 11$ and $130 \pm 15$ vs. $115 \pm 14,39 \pm 8$ and $124 \pm$ $15 \mathrm{mmHg}$ ( $p<0.001$ for all). Following adjustment all three BP's were higher in patients with retinopathy ( $p=$ 0.001 for all). Per 1 SD increase in 24 h-CASP, 24 h-CPP and $24 \mathrm{~h}-\mathrm{SBP}$, the OR for presence of retinopathy was 4.4 (2.0-9.6), 1.8 (1.2-2.7) and 3.7 (1.9-7.5) $(p<0.001$ for all) (Table 5). If including total cholesterol and body

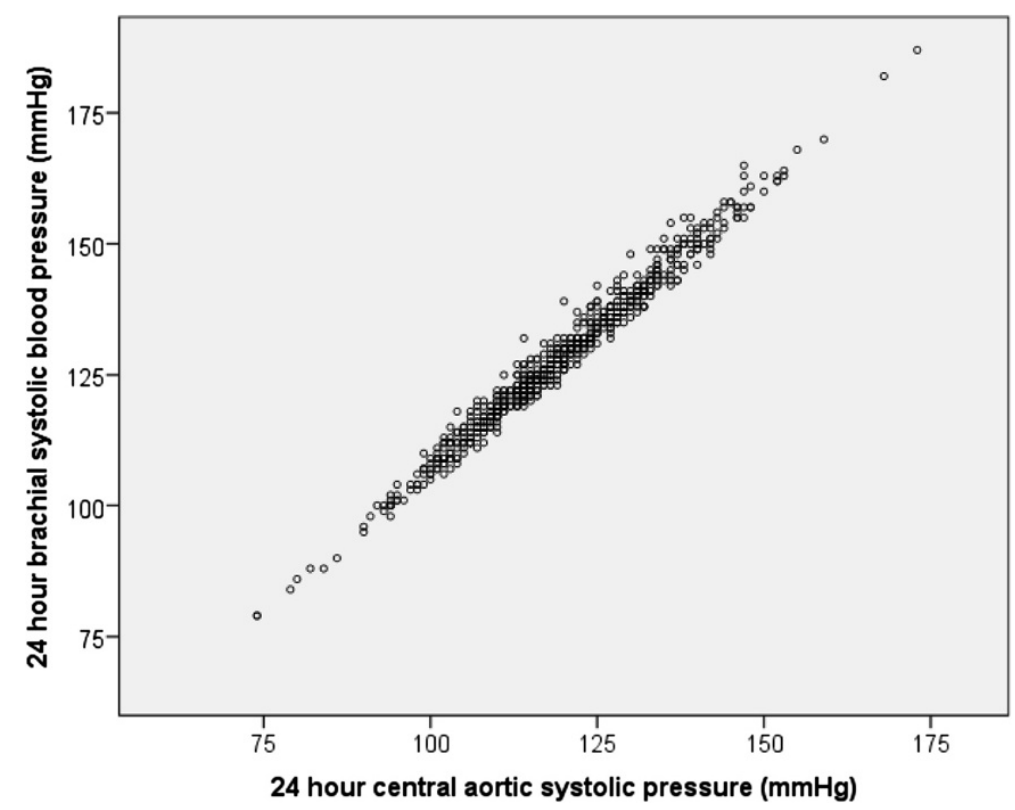

Figure 2 Scatter plot for 24 h-CASP and 24 h-SBP. $R=0.99, p<0.001$. 
Table 5 Adjusted odds ratios between hemodynamic variables and diabetic complications

\begin{tabular}{|c|c|c|c|c|}
\hline Complications & Patients with disease/ without disease & $\begin{array}{c}24 \mathrm{~h} \text {-CASP } \\
(1 \mathrm{SD}=14.2 \mathrm{mmHg})\end{array}$ & $\begin{array}{c}24 \mathrm{~h}-\mathrm{CPP} \\
(1 \mathrm{SD}=10.7 \mathrm{mmHg})\end{array}$ & $\begin{array}{c}24 \mathrm{~h}-\mathrm{SBP} \\
(1 \mathrm{SD}=15.6 \mathrm{mmHg})\end{array}$ \\
\hline Cardiovascular disease $^{*}$ & $n=134 / 495$ & $3.19(1.68-6.05)^{\ddagger}$ & $1.43(1.01-2.02)^{\S}$ & $2.39(1.32-4.33)^{\S}$ \\
\hline Left ventricular hypertrophy $^{\dagger}$ & $n=27 / 602$ & $2.51(0.98-6.45)$ & $1.50(0.98-2.30)$ & $2.14(0.92-5.01)$ \\
\hline Retinopathy ${ }^{*}$ & $\mathrm{n}=507 / 122$ & $4.41(2.03-9.57)^{\ddagger}$ & $1.77(1.17-2.68)^{\S}$ & $3.72(1.85-7.47)^{\ddagger}$ \\
\hline Autonomic dysfunction $^{*}$ & $n=350 / 237$ & $3.25(1.65-6.41)^{\S}$ & $1.64(1.12-2.639)^{\S}$ & $2.89(1.54-5.42)^{\S}$ \\
\hline
\end{tabular}

Values are odds ratios and $95 \%$ confidence intervals. Odds ratios are per 1 standard deviation (SD) increase in blood pressure.

*Adjusted for gender, age, $24 \mathrm{~h}-\mathrm{MAP}, 24 \mathrm{~h}-\mathrm{HR}$ urinary albumin excretion rate, estimated glomerular filtration rate, $\mathrm{HbA}_{1 \mathrm{c}}, \mathrm{smoking}$ and antihypertensive treatment. $24 \mathrm{~h}$-CASP is also adjusted for office CASP, $24 \mathrm{~h}$-CPP for office CPP and $24 \mathrm{~h}$-SBP for office SBP.

${ }^{+}$Adjusted for gender, age and 24 h-MAP due to low frequency.

${ }^{\ddagger} p<0.001,{ }^{\S} p<0.05$

mass index in the adjusted model, $p$-values for retinopathy were $<0.001$ for $24 \mathrm{~h}$-CASP, 0.004 for $24 \mathrm{~h}$-CPP and $<0.001$ for $24 \mathrm{~h}$-SBP.

$24 \mathrm{~h}-\mathrm{CASP}, 24 \mathrm{~h}-\mathrm{CPP}$ and $24 \mathrm{~h}-\mathrm{SBP}$ in patients with vs. without autonomic dysfunction

Autonomic dysfunction was present in 350 (59.4\%) of 587 assessed patients. Patients with vs. without autonomic dysfunction had $24 \mathrm{~h}$-CASP, $24 \mathrm{~h}$-CPP and $24 \mathrm{~h}-\mathrm{SBP}$ of $121 \pm 14,47 \pm 11$ and $130 \pm 16$ vs. $117 \pm 12,40 \pm 8$ and $126 \pm 13 \mathrm{mmHg}$ ( $p<0.001$ for all). Following adjustment, $24 \mathrm{~h}$-CASP, $24 \mathrm{~h}$-CPP and $24 \mathrm{~h}-\mathrm{SBP}$ remained significantly higher in patients with autonomic dysfunction $(p=0.001$ for all). Per 1 SD increase in 24 h-CASP, $24 \mathrm{~h}$-CPP and $24 \mathrm{~h}$-SBP the OR for presence of autonomic dysfunction was 3.3 (1.7-6.4), $1.6(1.1-2.4)$ and 2.9 (1.5-5.4) $(p=0.001$ for all) (Table 5). If we further included total cholesterol and body mass index in the adjusted model, $p$-values for CVD were $0.001,0.006$ and 0.002 for 24 h-CASP, 24 $\mathrm{h}-\mathrm{CPP}$ and $24 \mathrm{~h}-\mathrm{SBP}$, respectively.

\section{Discussion}

This is the first study to measure 24 h-CASP and 24 $\mathrm{h}-\mathrm{CPP}$ in patients with type 1 diabetes. The adjusted values of $24 \mathrm{~h}$-CASP and $24 \mathrm{~h}$-CPP was lower in controls compared to normoalbuminuric patients, and associated with increasing degree of albuminuria. Furthermore, 24 h-CASP and $24 \mathrm{~h}$-CPP was higher in patients with a history of CVD, retinopathy and autonomic dysfunction, but similar in patients with and without LVH on ECG. Importantly, the positive associations were present despite rigorous adjustment for baseline characteristics including brachial 24 h-MAP. If we further included office CASP or office $\mathrm{CPP}$ in the adjustments, both $24 \mathrm{~h}$-CASP and $24 \mathrm{~h}-\mathrm{CPP}$ remained significantly $(p \leq 0.045)$ associated with all complications except albuminuria (data not shown), suggesting additional risk information of 24 hour measurements as compared to office measurement. Furthermore, 24 h-CASP was closer associated to diabetic complications as compared to $24 \mathrm{~h}-\mathrm{SBP}$.

As expected, normoalbuminuric type 1 diabetes patients had higher 24 h-CASP and 24 h-CPP than controls. Patients with type 1 diabetes are known to develop accelerated arterial stiffness [26] caused by multifactorial mechanisms including increased production of advance glycation end products [27] and increased oxidative stress [28]. Furthermore, insulin resistance impairs the ability of insulin to decrease pressure augmentation and CASP [29]. However, controls and normoalbuminuric patients with short diabetes duration had similar 24 h-CASP and 24 h-CPP, consistent with the likelihood that arterial damage caused by diabetes is a later complication, not appearing until > 10 years of diabetes duration.

Increasing degree of albuminuria was independently associated with higher $24 \mathrm{~h}$-CASP and $24 \mathrm{~h}$-CPP. We expected this, as albuminuria has been shown to be associated with arterial stiffness [30]. However, our study is the first to measure $24 \mathrm{~h}$-CASP and $24 \mathrm{~h}$-CPP in patients with type 1 diabetes and to demonstrate a relationship between albuminuria and both $24 \mathrm{~h}$-CASP and $24 \mathrm{~h}$-CPP, independent of MAP, kidney function and conventional risk factors.

Presence of CVD was independently associated with higher $24 \mathrm{~h}$-CASP and $24 \mathrm{~h}$-CPP. CASP reflects the afterload on the heart, and as such, it may be a superior indicator of cardiovascular health, as indicated by a closer association with the risk of CVD and to constitute a better treatment target than brachial BP. Increasing CPP results from a combination of higher CASP and lower diastolic central BP. As cardiac perfusion occurs in diastole it is conceivable, that a higher CPP will compromise perfusion, which could indicate that CPP may also be a strong CVD risk marker.

An association between retinopathy and central BP has never before been investigated, although others have shown elevated brachial BP (> 130/90 mmHg) in type 2 diabetes to influence development of retinopathy [31] and high brachial BP (> 150/90 $\mathrm{mmHg}$ ) in type 1 diabetes to enhance progression of retinopathy [32]. We now show an independent association with central BP and retinopathy in type 1 diabetes patients.

Longer diabetes duration with presence of autonomic dysfunction does affect BP regulation. This is partly due to autonomic dysfunction being associated with altered vascular adrenoceptor sensitivity and catecholamine release $[33,34]$, altered renin release [35] and the concurrent 
development of arterial stiffness [36] and other diabetic complications [25]. Thus, by demonstrating an association between autonomic dysfunction and $24 \mathrm{~h}$ central BP our data concurs with and extends previous findings.

The close correlation between $24 \mathrm{~h}$-CASP and $24 \mathrm{~h}-\mathrm{SBP}$ is understandable, as both were calculated from the same radial pulse wave. Given this close correlation, 24 h-CASP may not be superior to $24 \mathrm{~h}$-SBP. However, we show that measurements of $24 \mathrm{~h}$-CASP are feasible, and that values are strongly associated with diabetic complications, independently of brachial 24 h-MAP. Furthermore, we also exposed $24 \mathrm{~h}$-CPP to be associated with diabetic complications, and the correlation between $24 \mathrm{~h}-\mathrm{CPP}$ and $24 \mathrm{~h}-\mathrm{SBP}$ was much weaker. Thus, despite the correlations between central and brachial BPs, the former may offer additional risk predictive value. This is in accordance with other studies, which have documented central BP to be closer associated with end organ damage [37] and superior to brachial BP in predicting outcome $[8,9]$, although, this was not confirmed in a recent meta-analysis [8]. Furthermore, central BP is associated with left ventricular mass in type 2 diabetes [38] and with left ventricular function in patients with abnormal diastolic function [39], commonly present in diabetes [40]. This is in accordance with our finding of higher 24 h-CASP in patients with LVH, although the significance attenuated on adjustment, which may however be due to lack of power.

In a future perspective, the $24 \mathrm{~h}$-CASP and $24 \mathrm{~h}$-CPP may offer additional predictive value to $24 \mathrm{~h}$-SBP in patients with type 1 diabetes. However, whether these methods of evaluating central stiffness will add prognostic information or, if there is any prognosis superiority between them, can only be determined in prospective studies. If subtle differences in 24 h-CASP and 24 h-SBP impact on outcome, targeting control of CASP rather than SBP may be more efficient in prevention of complications. The CAFE study, a sub-study of the ASCOT trial, investigated the effect of reducing CASP, and showed calcium blockers and beta blockers to exhibit different effect on CASP despite similar effect on SBP [13]. Another study showed reductions in B-type natriuretic peptide (a peptide secreted by the ventricles in response to strain and a marker of heart failure) in patients treated with nicorandil, likely secondary to reduced CASP [41], suggesting risk reduction associated with decreased CASP. Finally, a recent study demonstrated a reduction in left ventricular mass following treatment with perindopril and indapamide [42], which could be attributable to reduced CASP [39].

We suggest that CASP and CPP may supplement the predictive value of brachial $\mathrm{BP}$ in patients with type 1 diabetes. Moreover, central BP could be a future target for BP monitoring and control. Although, follow-up of this and other future prospective studies are required to verify if modifying CASP and/or CPP may supplement or even exceed the predictive value of modifying brachial $\mathrm{BP}$ on diabetic complications.

\section{Strengths and limitations}

The $24 \mathrm{~h}$-CASP and $24 \mathrm{~h}$-CPP was measured by a wrist bound tonometric device. This device has previously been validated with other non-invasive and invasive measurements [19,21,22]. More recently, Komori et al. showed that arm positioning did not affect BP measurements by the BPro device [20]. Adjustment were made for 24 h-MAP rather than $24 \mathrm{~h}$-SBP, -DBP or pulse pressure (PP) - PP, as MAP represents steady components of the BP, while SBP and PP contain pulsatile components and represent surrogates for arterial stiffness. Furthermore, 24 h-SBP, 24 h-CASP and 24 h-CPP were derived from the same pulse wave. Participants in the control group were compared to patients with short diabetes duration and normoalbuminuria. They were not fully matched on several covariates, including age. This could account for the lack of differences in the blood pressures between these two groups. We did however perform aggressive adjustments to compensate for this. The groups of patients with vs. without LVH were different in size, which limits the statistical power of these analyses. Furthermore, the diagnosis of LVH was solely based on ECG's, which has a lower specificity and sensitivity than cardiac imaging.

We did adjust for antihypertensive treatment in general. However, it was not possible to compare patients receiving different single agent regiments, as most patients received several different agents.

Major strengths are the remarkably high sample size, and the study being from a single center, why the cohort was likely rather homogenous and receiving similar treatment. The majority of patients had been followed at the Steno Diabetes Center for more than a decade, rendering the information on diabetic complications very reliable.

\section{Conclusions}

This is the first study to measure $24 \mathrm{~h}$-CASP and $24 \mathrm{~h}$-CPP in patients with type 1 diabetes. The 24 h-CASP and 24 $\mathrm{h}$-CPP was increased in patients with type 1 diabetes compared to controls and increased with albuminuria, CVD, retinopathy and autonomic dysfunction independently of covariates. Furthermore, $24 \mathrm{~h}$-CASP appeared to be stronger associated with complications as compared to $24 \mathrm{~h}-\mathrm{SBP}$. As measurement of $24 \mathrm{~h}$ ambulatory central BP is now feasible, further studies are required to determine its prognostic significance in patients with diabetes.

\section{Abbreviations}

AHT: Antihypertensive treatment; AMBP: 24-hour ambulatory blood pressure; BPro: BPro HealthStats; CVD: Cardiovascular disease; CASP: Central aortic systolic pressure; CPP: Central pulse pressure; DBP: Diastolic blood pressure; ECG: Electrocardiogram; eGFR: Estimated glomerular filtration rate; HR: Heart 
rate; MAP: Mean arterial pressure; PP: Pulse pressure; SBP: Systolic blood pressure; UAER: Urinary albumin excretion rate.

\section{Competing interests}

Williams is a National Institutes for Health Research (NIHR) Senior Investigator, supported by the University College London NIHR Biomedical Research Centre, London UK. Williams and Lacy have worked in scientific collaboration with HealthStats, Singapore developing methods for noninvasive derivation of central pressures from radial artery wave forms. Theilade, Lajer, Hansen, Joergensen, Persson, Andrésdottir, Reinhard, Nielsen and Rossing have received no grants/support and have nothing to disclose and no conflicts of interest.

\section{Authors' contributions}

ST researched and analysed the data, contributed to the discussion, wrote and edited the manuscript. ST is the guarantor for the manuscript. ML researched the data, contributed to the discussion and reviewed the manuscript. TWH analysed the data, contributed to the discussion, edited and reviewed the manuscript. CJ, FP and HR researched the data and reviewed the manuscript. GA and SEN researched the data. PL and BW contributed to the data analyses, and the discussion and edited the manuscript. PR researched and analysed the data, contributed to the discussion and reviewed the manuscript. All authors read and approved the final manuscript.

\section{Author details}

${ }^{1}$ Steno Diabetes Center, Niels Steensensvej 1, 2820 Gentofte, Denmark. ${ }^{2}$ The Institute of Cardiovascular Science and National Institute for Health Research Biomedical Research Centre, University College London, London, UK. ${ }^{3}$ Aarhus University, Aarhus, Denmark. ${ }^{4}$ University of Copenhagen, Copenhagen, Denmark.

Received: 21 August 2013 Accepted: 23 August 2013

Published: 27 August 2013

\section{References}

1. Chen G, McAlister FA, Walker RL, Hemmelgarn BR, Campbell NR: Cardiovascular outcomes in framingham participants with diabetes: the importance of blood pressure. Hypertension 2011, 57(5):891-897.

2. Parving HH: Impact of blood pressure and antihypertensive treatment on incipient and overt nephropathy, retinopathy, and endothelial permeability in diabetes mellitus. Diabetes Care 1991, 14(3):260-269.

3. Cederholm J, Eeg-Olofsson K, Eliasson B, Zethelius B, Gudbjornsdottir S: A new model for 5 -year risk of cardiovascular disease in Type 1 diabetes; from the Swedish National Diabetes Register (NDR). Diabet Med 2011, 28(10):1213-1220.

4. Akkanen MJ, Kivela SL, Koistinen V, Sintonen H, Tuomilehto J: Inpatient care of patients with type 1 diabetes mellitus by duration of diabetes and sex: a nationwide population-based longitudinal study. Risk Manag Healthc Policy 2009, 2:55-64.

5. Dolan E, Stanton A, Thijs L, Hinedi K, Atkins N, McClory S, et al: Superiority of ambulatory over clinic blood pressure measurement in predicting mortality: the Dublin outcome study. Hypertension 2005, 46(1):156-161.

6. Niiranen TJ, Hanninen MR, Johansson J, Reunanen A, Jula AM: Home-measured blood pressure is a stronger predictor of cardiovascular risk than office blood pressure: the Finn-Home study. Hypertension 2010, 55(6):1346-1351.

7. Pini R, Cavallini MC, Palmieri V, Marchionni N, Di BM, Devereux RB, et al: Central but not brachial blood pressure predicts cardiovascular events in an unselected geriatric population: the ICARe Dicomano Study. J Am Coll Cardiol 2008, 51(25):2432-2439.

8. Vlachopoulos C, Aznaouridis K, O'Rourke MF, Safar ME, Baou K, Stefanadis C: Prediction of cardiovascular events and all-cause mortality with central haemodynamics: a systematic review and meta-analysis. Eur Heart J 2010, 31(15):1865-1871.

9. Wang KL, Cheng HM, Chuang SY, Spurgeon HA, Ting CT, Lakatta EG, et al: Central or peripheral systolic or pulse pressure: which best relates to target organs and future mortality? J Hypertens 2009, 27(3):461-467.

10. Brooks B, Molyneaux L, Yue DK: Augmentation of central arterial pressure in type 1 diabetes. Diabetes Care 1999, 22(10):1722-1727.
11. Franklin SS, Gustin W, Wong ND, Larson MG, Weber MA, Kannel WB, et al: Hemodynamic patterns of age-related changes in blood pressure. The Framingham Heart Study. Circulation 1997, 96(1):308-315.

12. Schram MT, Henry RM, van Dijk RA, Kostense PJ, Dekker JM, Nijpels G, et al: Increased central artery stiffness in impaired glucose metabolism and type 2 diabetes: the Hoorn Study. Hypertension 2004, 43(2):176-181.

13. Williams B, Lacy PS, Thom SM, Cruickshank K, Stanton A, Collier D, et al: Differential impact of blood pressure-lowering drugs on central aortic pressure and clinical outcomes: principal results of the Conduit Artery Function Evaluation (CAFE) study. Circulation 2006, 113(9):1213-1225.

14. Matsui Y, Eguchi K, O'Rourke MF, Ishikawa J, Miyashita H, Shimada K, et al: Differential effects between a calcium channel blocker and a diuretic when used in combination with angiotensin II receptor blocker on central aortic pressure in hypertensive patients. Hypertension 2009, 54(4):716-723.

15. London GM, Asmar RG, O'Rourke MF, Safar ME: Mechanism(s) of selective systolic blood pressure reduction after a low-dose combination of perindopril/indapamide in hypertensive subjects: comparison with atenolol. J Am Coll Cardiol 2004, 43(1):92-99.

16. Williams B, Lacy PS, Baschiera F, Brunel P, Dusing R: Novel Description of the 24-Hour Circadian Rhythms of Brachial Versus Central Aortic Blood Pressure and the Impact of Blood Pressure Treatment in a Randomized Controlled Clinical Trial: The Ambulatory Central Aortic Pressure (AmCAP) Study. Hypertension 2013, 61(6):1168-1176.

17. Rossing $\mathrm{P}$, Hougaard $\mathrm{P}$, Parving $\mathrm{HH}$ : Risk factors for development of incipient and overt diabetic nephropathy in type 1 diabetic patients: a 10-year prospective observational study. Diabetes Care 2002, 25(5):859-864

18. Nair D, Tan SY, Gan HW, Lim SF, Tan J, Zhu M, et al: The use of ambulatory tonometric radial arterial wave capture to measure ambulatory blood pressure: the validation of a novel wrist-bound device in adults. $J$ Hum Hypertens 2008, 22(3):220-222.

19. Williams B, Lacy PS, Yan P, Hwee CN, Liang C, Ting CM: Development and validation of a novel method to derive central aortic systolic pressure from the radial pressure waveform using an $\mathrm{N}$-point moving average method. J Am Coll Cardiol 2011, 57(8):951-961.

20. Komori T, Eguchi K, Hoshide S, Williams B, Kario K: Comparison of wrist-type and arm-type 24-h blood pressure monitoring devices for ambulatory use. Blood Press Monit 2013, 18(1):57-62.

21. Ott $C$, Haetinger $S$, Schneider MP, Pauschinger M, Schmieder RE: Comparison of two noninvasive devices for measurement of central systolic blood pressure with invasive measurement during cardiac catheterization. J Clin Hypertens (Greenwich) 2012, 14(9):575-579.

22. Theilade S, Hansen TW, Joergensen C, Lajer M, Rossing P: Tonometric devices for central aortic systolic pressure measurements in patients with type 1 diabetes: comparison of the BPro and SphygmoCor devices. Blood Press Monit 2013, 18(3):156-160

23. O'Brien E, Asmar R, Beilin L, Imai Y, Mallion JM, Mancia G, et al: European Society of Hypertension recommendations for conventional, ambulatory and home blood pressure measurement. J Hypertens 2003, 21(5):821-848.

24. Pewsner D, Juni P, Egger M, Battaglia M, Sundstrom J, Bachmann LM: Accuracy of electrocardiography in diagnosis of left ventricular hypertrophy in arterial hypertension: systematic review. BMJ 2007, 335(7622):711.

25. Vinik Al, Maser RE, Mitchell BD, Freeman R: Diabetic autonomic neuropathy. Diabetes Care 2003, 26(5):1553-1579.

26. Llaurado G, Ceperuelo-Mallafre V, Vilardell C, Simo R, Freixenet N, Vendrell J, et al: Arterial stiffness is increased in patients with type 1 diabetes without cardiovascular disease: a potential role of low-grade inflammation. Diabetes Care 2012, 35(5):1083-1089.

27. Sell DR, Monnier VM: Molecular basis of arterial stiffening: role of glycation - a mini-review. Gerontology 2012, 58(3):227-237.

28. Delles C, Zimmerli LU, McGrane DJ, Koh-Tan CH, Pathi VL, McKay AJ, et al: Vascular stiffness is related to superoxide generation in the vessel wall. J Hypertens 2008, 26(5):946-955.

29. Westerbacka J, Uosukainen A, Makimattila S, Schlenzka A, Yki-Jarvinen H: Insulin-induced decrease in large artery stiffness is impaired in uncomplicated type 1 diabetes mellitus. Hypertension 2000, 35(5):1043-1048.

30. Bouchi R, Babazono T, Mugishima M, Yoshida N, Nyumura I, Toya K, et al: Arterial stiffness is associated with incident albuminuria and decreased 
glomerular filtration rate in type 2 diabetic patients. Diabetes Care 2011, 34(12):2570-2575.

31. Raman R, Gupta A, Kulothungan V, Sharma T: Prevalence and Risk Factors of Diabetic Retinopathy in Subjects with Suboptimal Glycemic, Blood Pressure and Lipid Control. Sankara Nethralaya Diabetic Retinopathy Epidemiology and Molecular Genetic Study (SN-DREAMS, Report 33). Curr Eye Res 2012, 37(6):513-523.

32. Hammes HP, Kerner W, Hofer S, Kordonouri O, Raile K, Holl RW: Diabetic retinopathy in type 1 diabetes-a contemporary analysis of 8,784 patients. Diabetologia 2011, 54(8):1977-1984.

33. Christensen NJ: Plasma catecholamines in long-term diabetics with and without neuropathy and in hypophysectomized subjects. J Clin Invest 1972, 51(4):779-787.

34. Hilsted J, Richter E, Madsbad S, Tronier B, Christensen NJ, Hildebrandt P, et al: Metabolic and cardiovascular responses to epinephrine in diabetic autonomic neuropathy. N Engl J Med 1987, 317(7):421-426.

35. Campbell IW, Ewing DJ, Anderton JL, Thompson JH, Horn DB, Clarke BF: Plasma renin activity in diabetic autonomic neuropathy. Eur $J$ Clin Invest 1976, 6(5):381-385.

36. Meyer C, Milat F, McGrath BP, Cameron J, Kotsopoulos D, Teede HJ: Vascular dysfunction and autonomic neuropathy in Type 2 diabetes. Diabet Med 2004, 21(7):746-751.

37. Zhang Y, Li Y, Ding FH, Sheng CS, Huang QF, Wang JG: Cardiac structure and function in relation to central blood pressure components in Chinese. J Hypertens 2011, 29(12):2462-2468

38. Sharman JE, Fang ZY, Haluska B, Stowasser M, Prins JB, Marwick TH: Left ventricular mass in patients with type 2 diabetes is independently associated with central but not peripheral pulse pressure. Diabetes Care 2005, 28(4):937-939.

39. Tartiere-Kesri L, Tartiere JM, Logeart D, Beauvais F, Cohen SA: Increased proximal arterial stiffness and cardiac response with moderate exercise in patients with heart failure and preserved ejection fraction. $J$ Am Coll Cardiol 2012, 59(5):455-461.

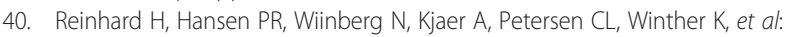
NT-proBNP, echocardiographic abnormalities and subclinical coronary artery disease in high risk type 2 diabetic patients. Cardiovasc Diabetol 2012, 11:19.

41. Kimura T, Kitamura H, Inoue K, Kawada N, Matsui I, Nagasawa Y, et al: Effects of nicorandil on the reduction of BNP levels in patients with chronic kidney disease. Clin Exp Nephrol 2011, 15(6):854-860

42. de Luca N, Asmar RG, London GM, O'Rourke MF, Safar ME: Selective reduction of cardiac mass and central blood pressure on low-dose combination perindopril/indapamide in hypertensive subjects. J Hypertens 2004, 22(8):1623-1630.

doi:10.1186/1475-2840-12-122

Cite this article as: Theilade et al: 24-hour central aortic systolic pressure and 24-hour central pulse pressure are related to diabetic complications in type 1 diabetes - a cross-sectional study.

Cardiovascular Diabetology 2013 12:122.

\section{Submit your next manuscript to BioMed Central and take full advantage of:}

- Convenient online submission

- Thorough peer review

- No space constraints or color figure charges

- Immediate publication on acceptance

- Inclusion in PubMed, CAS, Scopus and Google Scholar

- Research which is freely available for redistribution

Submit your manuscript at www.biomedcentral.com/submit
Ciomed Central 